\title{
Burdur Koşullarında Bazı Şeker Mısır Çeşitlerinin Performansları
}

\author{
Mutlu ŞAHIN ${ }^{(D)}$, Burhan KARA (iD) 2* \\ ${ }^{1}$ Devlet Su İşleri, Burdur \\ ${ }^{2}$ Isparta Uygulamalı Bilimler Üniversitesi, Ziraat Fakültesi, Isparta \\ Geliş Tarihi (Received): 26.01.2021, Kabul Tarihi (Accepted): 07.07.2021 \\ $\square$ Sorumlu Yazar (Corresponding author*): burhankara@isparta.edu.tr \\ (C) +902462146247 吾 +902462146399
}

$\overline{o ̈ z}$

Araştırma, Burdur ekolojik koşullarında bazı şeker mısır çeşitlerinin taze koçan özelliklerini araştırmak amacıyla 2019 ve 2020 yıllarında yürütülmüştür. Deneme; "Khan, Mirza, Vega, Bond, Batem tatı, Calipos ve Merit" F1 şeker mısır çeşitleri kullanılarak, tesadüf blokları deneme desenine göre 3 tekerrürlü olarak kurulmuştur. Her iki yılda da, incelenen özelikler bakımından çeşitler arasındaki farklar istatistik $(P \leq 0.05$ ve $P \leq 0.01)$ olarak önemli olmuş, en yüksek ve en düşük değerler çeşitlere ve yıllara göre değişmiştir. Burdur koşullarında birinci yıl 85-96. gün ve ikinci yıl 83-91. gün arasında taze koçan hasadı yapılmıştır. Araştırmada 2019 ve 2020 yıllarında; koçan boyu 18,2-21,6 cm ve 17,1$24,1 \mathrm{~cm}$, koçan çapı 37,6-51,0 mm ve 46,0-52,1 mm, koçanda tane sayısı 502,3-703,3 adet/koçan ve 544,0-780,6 adet/koçan, tek koçan ağırlığı 275,6-304,0 g ve 188,1-316,9 g ve pazarlanabilir koçan sayısı 5553,4-6131,7 adet/da ve 5423,0-6215,3 adet/da arasında değişmiştir. Çalışma sonucuna göre, Burdur koşullarında, şeker mısırın koçan boyu, koçan çapı özellikleri ve pazarlanabilir mısır sayıları göz önüne alındığında "Vega, Mirza ve Merit" çeşitlerinin önerilmektedir.

Anahtar Kelimeler: Burdur, koçan özellikleri, koçan sayısı, şeker mısır

\section{Performances of Some Sweet Corn Cultivars in Burdur Conditions}

\begin{abstract}
The research was carried out in 2019 and 2020 to investigate the fresh ear characteristics of some sweet corn varieties in Burdur ecological conditions. The experiment was set up according to a randomized complete block design with three replicates using the "Khan, Mirza, Vega, Bond, Batem tatlı, Calipos and Merit" $F_{1}$ sweet corn cultivars. Differences among the cultivars in term of examined characteristics were statistical $(P \leq 0.05$ and $P \leq 0.01)$ significant in both years, and the highest and the lowest value varied according to cultivars and years. Fresh corn was harvested between 85-96 $6^{\text {th }}$ days in the first year and 83-91 th days in the second year in Burdur conditions. In the research in 2019 and 2020; the ear length $18.2-21.6 \mathrm{~cm}$ and $17.1-24.1 \mathrm{~cm}$, ear diameter 37.6-51.0 $\mathrm{mm}$ and 46.0-52.1 mm, number of grains per ear 502.3-703.3 pcs/cob and 544.0-780.6 pcs/cob, single ear weight 275.6-304.0 $\mathrm{g}$ and $188.1-316.9 \mathrm{~g}$ and number of marketable cobs changed between 5553.4-6131.7 pcs/da and 5423.0-6215.3 pcs/da. According to the result of the study, "Vega, Mirza and Merit" $F_{1}$ cultivars were recommended as fresh corn at considering ear length, ear diameter ear characteristics and number of marketable sweet corn in Burdur conditions.
\end{abstract}

Keywords: Burdur, ear characteristics, ear number, sweet corn 


\section{GíRiş}

Şeker mısırı değişik kullanım alanları ile dünyada ve ülkemizde hızla tüketimi artan bir mısır alttürüdür. Süt olum dönemi sonunda hasat edildiğinde diğer mısır alttürlerinden daha fazla şeker oranına sahiptir. Süt olum döneminde hasat edilen şeker mısır tane içeriği bakımından diğer mısır tiplerinden farklıdır ve bu özelliği ile taze tüketime en uygun mısır çeşididir. Koçanları kaynatılarak ve közlenerek doğrudan tüketildiği gibi; taneler konserve yapılarak veya dondurularak da gıda sanayisinde değerlendirilmektedir. Bu sayede tüketimi yaz ayları ile sınırlı kalmayıp, geniş bir döneme yayılan bir besin kaynağıdır (Köycü ve Yanıkoğlu, 1987).

Burdur ili yüzölçümünün \%57,9'u tarıma elverişli birinci ve ikinci sınıf arazilerden oluşmaktadır ve tarım arazisinin \%44,6'sı sulanmaktadır (Anonim, 2020). Bu arazilerde şekerpancarı, silajlık mısır ve sebze tarımı yapılmaktadır. Yüksek sulama imkânına sahip olan bu arazilerde ürün çeşitliliğinin artırılması, kısa vejetasyon süresine sahip alternatif ürünlerin ekilmesi tarımsal üretime katkı sunacaktır. Şeker mısırı ekimden itibaren 75-80 günde süt olum döneminde hasat edilebilmektedir. Şeker mısır kısa vejetasyon dönemine sahip olduğu için araziyi erken terk etmektedir. Bu nedenle toprağı fazla yormamakta, kendisinden sonra başka ürünlerin ekilmesine olanak sağlamaktadır.

Şeker mısırda daha fazla şeker taşıyan "Se" geni ile "Su-1" geninin kombine edilmesiyle Sh-2" geni taşıyan süper tatlı mısır çeşitler geliştirilmiştir. Bu çeşitler standart şeker mısır çeşitlerine göre 2 veya 3 kat daha fazla şeker ihtiva etmektedir (Eser ve Soylu, 2020). Şeker mısırın tanesinde olduğu gibi diğer mısır alttürlerine göre yeşil aksamında şeker oranı yüksektir. Taze tüketim için mısır süt olum dönemi sonunda koçanlar koparılır. Bu dönem koçan püskülü çıkışından sonraki 3 haftalık bir süredir. Bu dönemde koçan yaprakları yeşildir ve tanelerin su oranı \%60-65 dolaylarındadır. Bu nedenle hayvan yemi olarak kullanılabilmektedir. Bunun yanında dekara 5 000-10 000 arasında pazarlanabilir koçan sayısı ile sulanabilir alanlarda birçok ürün ile rekabet edebilmektedir. Yıldırkan ve Kara (2020) dekara koçan sayısının 10384,5-10732,0 adet, Kara ve Uygur (2020) 6371,9-6393,6 adet ve Kara (2011) 5638,0-6480,0 adet arasında değiştiğini bildirmişlerdir. Sönmez ve ark. (2013) şeker mısır çeşitlerinin taze koçan uzunluğunun 21,9-23,8 cm, koçan çapının 48,0$54,1 \mathrm{~mm}$ ve koçan ağırlığının 338-406 g ve Ağaçkesen ve Öktem (2020) taze koçan uzunluğunun 17,3-20,2 $\mathrm{cm}$ ve taze koçan veriminin 1103,2-1889,8 kg/da arasında değiştiğini rapor etmişlerdir. Tüm Türkiye'de olduğu gibi Burdur da şeker mısırın ekim ve üretim alanı ile ilgili bir istatistik yoktur. Şeker mısır Burdur'da sulanabilen tarım arazilerine ekim nöbetine girebilecek ve ekonomik olarak rekabet edebilecek bir bitkidir. Bu nedenle, araştırma Burdur koşullarında şeker mısır çeşitlerinin taze koçan özellikleri ve pazarlanabilir koçan sayısını belirlemek amacıyla yürütülmüştür.

\section{MATERYAL VE YÖNTEM}

Araştırma, "Khan, Mirza, Vega, Bond, Batem tatlı, Calipos ve Merit" $F_{1}$ şeker mısır çeşitleri kullanılarak 2019 ve 2020 yıllarında tesadüf blokların deneme desenine göre üç tekerrürlü olarak Burdur merkez koşullarında yürütülmüştür.

Denemenin yürütüldüğü 2019 ve 2020 yılları MayısEylül aylarına ilişkin toplam yağış miktarı sırasıyla, $133,7 \mathrm{~mm}$ ve $170,2 \mathrm{~mm}$ olmuş, uzun yıllar ortalaması ise $114,4 \mathrm{~mm}$ olarak gerçekleşmiştir. Bu dönem (Mayıs-Eylül) içerisinde ortalama sıcaklık sırasıyla, $21,9^{\circ} \mathrm{C}$ ve $22,5^{\circ} \mathrm{C}$ olup, uzun yıllar sıcaklık ortalamasından $\left(21,3^{\circ} \mathrm{C}\right)$ yüksek olurken, nispi nem oranı ise sırasıyla, $\% 37,9$ ve \%36,9 olup, uzun yıllar ortalamasından $(\% 42,8)$ düşük olmuştur (Tablo 1).

Tablo 1. Deneme yıllarına (2019 ve 2020) ve uzun yıllara ait iklim verileri*

\begin{tabular}{|c|c|c|c|c|c|c|c|}
\hline \multirow{2}{*}{ İklim faktörleri } & \multicolumn{6}{|c|}{ Aylar } & \multirow{2}{*}{$\begin{array}{l}\text { Toplam / Or- } \\
\text { talama }\end{array}$} \\
\hline & Yıllar & Mayıs & Haziran & Temmuz & Ağustos & Eylül & \\
\hline \multirow{3}{*}{$\begin{array}{l}\text { Yağış } \\
(m m)\end{array}$} & 2019 & 25,2 & 81,3 & 9,24 & 0,8 & 17,2 & 133,7 \\
\hline & 2020 & 102,2 & 36,2 & 13,8 & 22,0 & 5,8 & 170,2 \\
\hline & Uzun yıllar & 44,1 & 28,8 & 19,8 & 9,6 & 15,2 & 114,4 \\
\hline \multirow{3}{*}{$\begin{array}{l}\text { Ortalama sı- } \\
\text { caklık }\left({ }^{\circ} \mathrm{C}\right)\end{array}$} & & 17,9 & 21,5 & 24,2 & 25,3 & 20,8 & 21,9 \\
\hline & 2020 & 16,7 & 20,4 & 26,9 & 25,4 & 23,4 & 22,5 \\
\hline & Uzun yıllar & 16,3 & 21,0 & 24,7 & 24,5 & 20,2 & 21,3 \\
\hline \multirow{3}{*}{$\begin{array}{l}\text { Nispi nem } \\
\text { (\%) }\end{array}$} & 2019 & 39,7 & 45,9 & 34,1 & 31,9 & 38,0 & 37,9 \\
\hline & 2020 & 43,8 & 41,6 & 30,6 & 32,4 & 36,2 & 36,9 \\
\hline & Uzun yıllar & 43,0 & 42,6 & 41,0 & 41,7 & 46,5 & 42,8 \\
\hline
\end{tabular}

${ }^{*}$ Burdur Meteoroloji İstasyonu iklim verileri 
Deneme alanı toprağı killi-tınlı bir yapıya sahip olup, bazik, kireç oranı yüksek ve organik madde oranı bakımından düşük düzeydedir (Tablo 2).

Tablo 2. Deneme alanı toprağının fiziksel ve kimyasal analiz sonuçları*

\begin{tabular}{lllll}
\hline Yıllar & Derinlik $(\mathrm{cm})$ & $\mathrm{pH}$ & Kireç $\mathrm{CaCO}_{3}(\%)$ & Organik madde $(\%)$ \\
\hline 2019 & $0-90$ & 8,09 & 35,40 & 1,03 \\
& & Bazik & Yüksek & Düşük \\
\hline 2020 & 0.90 & 8,02 & 31,41 & 1,23 \\
& & Bazik & Yüksek & Düşük \\
\hline
\end{tabular}

*: ISLAP laboratuvarında yapılmıştır

Denemeler, birinci ve ikinci yılda aralarında yaklaşık $500 \mathrm{~m}$ mesafe olan ayrı arazilerde kurulmuştur. Deneme toprağı ön bitkiden (buğday) sonra işlenmiş ve ilkbahara kadar boş bırakılmış, ekimden önce ikileme yapılarak, diskaro çekilmiş ve tohum yatağı hazırlanmıştır. Ekim 08/05/2019 ve 10/05/2020'de tarihlerinde yapılmıştır. Parsel sıra uzunluğu $5 \mathrm{~m}$ ve 4 sıra, bloklar arasında $2 \mathrm{~m}$, her parsel arasında bir sıra aralık bırakılmış, ekimden önce parsellere damla sulama boruları döşenerek $70 \mathrm{~cm}$ sıra arası ve $18 \mathrm{~cm}$ sıra üzeri mesafede $(70 \mathrm{~cm} \times 18 \mathrm{~cm})$, her ocağa iki tohum gelecek şekilde $3-4 \mathrm{~cm}$ derinliğinde ekim yapılmıştır. Çıkıştan sonra her ocakta bir bitki kalacak şekilde tekleme yapılmıştır. Ekimle birlikte taban gübresi olarak $15 \mathrm{~kg} / \mathrm{da}$ (15-15-15), çapalamayla birlikte bitki diz boyu (35-40 $\mathrm{cm}$ ) döneminde üst gübre olarak $12 \mathrm{~kg} /$ da üre uygulanmış, ekimden sonra çıkış yapana kadar ve çıkıştan sonra toprak nem düzeyi kontrol edilerek sulama yapılmıştır.

Taze koçan amacıyla hasat, çeşitlerin süt olum dönemin sonunda birinci yıl 01-12/08/2019 ve ikinci yıl 0412/08/2020 tarihlerinde yapılmıştır. Hasat edilen taze mısırlarda koçan boyu $(\mathrm{cm})$, koçan çapı $(\mathrm{mm})$, koçanda tane sayısı (adet/koçan), tek koçan ağırlığı (g) ve pazarlanabilir koçan sayısı (adet/da) ölçümleri yapılmıştır. Pazarlanabilir koçan sayısı; koçan boyuna göre 3 ayrı sınıfta yapılmıştır. (1). 15,2 cm (US Fancy), (2). 12,7 cm (US No. 1), (3). 10,2 cm (US No. 2) ve tek koçana ağırlığının 247,0 g/koçan (US No. 1)'dan az olmaması gerekmektedir (Lizaso ve ark., 2007).
Elde edilen verilerin varyans analizleri SAS istatistik paket programından faydalanılarak yapılmış ve ortalamalar arasındaki farkların önem düzeyleri LSD Testine $(P<0.05, P<0.01)$ göre belirlenmiştir.

\section{BULGULAR VE TARTIŞMA}

Burdur koşullarında süt olum döneminde çeşitlere bağı olarak; birinci yıl 85-96. günde ve ikinci yıl 83-91. günlerde taze haşlamalık/közlemelik şeker mısırı hasat edilmiştir. Denemede kullanılan şeker mısır çeşitlerinin hasat süreleri arasında 8 ile 11 gün fark olduğu belirlenmiştir. Bu farklılık çeşitlerin erkenci veya geçci olmalarına göre değişmiş, en erken "Vega ve Batem tatı" ve en geç "Merit çeşidi hasat edilmiştir. Şeker mısır çeşitleri kendi içinde erkenci (70-80 gün), orta erkenci (85-90 gün) ve geçci (95-110 gün) olarak sınıflandırılmaktadır (Szymanek ve ark., 2006). Taze tüketim amacıyla üretilen şeker mısırda, tüketimin geniş sürelere yayılması bakımından çeşitler arasında hasat zamanlarının farklı olması istenen bir durumdur.

Şeker mısırda koçan boyu, koçan çapı ve koçandaki tane sayısı bakımından yıllar arasındaki farklar istatistik olarak önemli olurken, tek koçan ağırlığı ve pazarlanabilir koçan sayısı açısından önemli fark ortaya çıkmamıştır (Tablo 3,4). İstatistik olarak önemli olan özeliklerin ikinci yıl ortalamaları birinci yıldan daha yüksek olmuştur. Bu farklılık ikinci yıl deneme alanı toprak yapısının nispeten (özellikle organik madde) daha iyi olmasında kaynaklanmış olabilir (Tablo 2). 
Burdur Koşullarında Bazı Şeker Mısır Çeşitlerinin Performansları

Tablo 3. Şeker mısır çeşitlerinin bazı koçan özellikleri

\begin{tabular}{|c|c|c|c|c|c|c|c|c|}
\hline \multirow[t]{2}{*}{ Çeşitler } & \multicolumn{2}{|c|}{ Koçan boyu $(\mathrm{cm})$} & \multicolumn{2}{|c|}{ Koçan çapı (mm) } & \multicolumn{2}{|c|}{$\begin{array}{l}\text { Koçana tane sayısı } \\
\text { (adet/koçan) }\end{array}$} & \multicolumn{2}{|c|}{$\begin{array}{l}\text { Tek koçan ağırlığı } \\
\text { (g/koçan) }\end{array}$} \\
\hline & 2019 & 2020 & 2019 & 2020 & 2019 & 2020 & 2019 & 2020 \\
\hline Khan & $19,6 \mathrm{abc}$ & $22,3 \mathrm{~b}$ & $49,3 a b$ & $47,0 \mathrm{~cd}$ & $564,3 \mathrm{~cd}$ & $680,3 \mathrm{~d}$ & $266,0 \mathrm{~cd}$ & $279,0 \mathrm{c}$ \\
\hline Mirza & 19,4 bc & $24,1 \mathrm{a}$ & $51,0 \mathrm{a}$ & $50,6 \mathrm{abc}$ & $638,0 a b$ & $780,6 \mathrm{a}$ & $304,0 \mathrm{a}$ & $300,0 a b$ \\
\hline Vega & 21,6 a & $21,9 \mathrm{bc}$ & $40,3 \mathrm{c}$ & $52,1 \mathrm{a}$ & $639,0 a b$ & $705,3 \mathrm{c}$ & 299,0 a & 314,3 a \\
\hline Bond & $20,4 a b$ & $20,8 \mathrm{~cd}$ & $38,3 \mathrm{c}$ & $51,3 a b$ & $623,0 \mathrm{bc}$ & $635,0 \mathrm{e}$ & $253,6 d$ & $303,4 a b$ \\
\hline Batem tatlı & $18,2 \mathrm{c}$ & $17,1 \mathrm{e}$ & $37,6 \mathrm{c}$ & $46,0 \mathrm{~d}$ & $502,3 d$ & $544,0 \mathrm{f}$ & $275,6 \mathrm{bc}$ & $188,1 \mathrm{~d}$ \\
\hline Calipos & $19,1 \mathrm{bc}$ & $19,7 \mathrm{~d}$ & $47,3 \mathrm{~b}$ & 49,3 a-d & $616,3 \mathrm{bc}$ & $692,0 \mathrm{~cd}$ & 285,0 b & 294,7 bc \\
\hline Merit & $20,0 \mathrm{abc}$ & $21,2 \mathrm{bc}$ & $48,3 \mathrm{ab}$ & $48,3 \mathrm{bcd}$ & 703,3 a & 729,7 b & $302,3 \mathrm{a}$ & $316,9 \mathrm{a}$ \\
\hline YIl ortalama & $19,7 \mathrm{~B}^{*}$ & $21,0 \mathrm{~A}$ & $44,6 B^{*}$ & $49,2 \mathrm{~A}$ & $612,3 B^{\star *}$ & $681,0 \mathrm{~A}$ & $283,7^{\text {öd }}$ & 285,3 \\
\hline LSD çeşit & 2,06 & 1,49 & 3,56 & 3,64 & 73,50 & 23,04 & 14,22 & 18,7 \\
\hline F değeri çeşit & 5,14 & 40,27 & 46,65 & 7,27 & 13,92 & 198,45 & 35,15 & 106,25 \\
\hline P değeri çeşit & 0,0078 & 0,0001 & 0,0001 & 0,0019 & 0,0001 & 0,0001 & 0,0001 & 0,0001 \\
\hline VK (\%) & 4,19 & 2,85 & 3,20 & 2,96 & 4,81 & 3,35 & 2,90 & 3,61 \\
\hline
\end{tabular}

Aynı sütunda benzer harfler ile gösterilen ortalamalar arasında istatistiksel olarak fark yoktur.

*, **: Sırasıyla $\mathrm{P} \leq 0.05$ ve $\mathrm{P} \leq 0.01$ düzeyinde önemli, öd: Önemli değil

Tablo 4. Şeker mısır çeşitlerinin koçan sayıları

\begin{tabular}{lllll}
\hline \multirow{2}{*}{ Çeşitler } & \multicolumn{4}{l}{ Pazarlanabilir koçan sayısı (adet/da-\%) } \\
\cline { 2 - 5 } & 2019 & $\%$ & 2020 & $\%$ \\
\hline Khan & $5562,0 \mathrm{~cd}$ & 72,3 & $5282.3 \mathrm{c}$ & 73.4 \\
Mirza & $6131,7 \mathrm{a}$ & 73,4 & $6215.3 \mathrm{a}$ & 76.6 \\
Vega & $5804,7 \mathrm{abc}$ & 76,0 & $5637.7 \mathrm{~b}$ & 75.8 \\
Bond & $5395,6 \mathrm{~d}$ & 76,6 & $5342.3 \mathrm{bc}$ & 77.9 \\
Batem tatlı & $5570,8 \mathrm{bcd}$ & 70,9 & $5423.0 \mathrm{bc}$ & 70.5 \\
Calipos & $5553,4 \mathrm{~cd}$ & 73,6 & $5528.0 \mathrm{bc}$ & 74.9 \\
Merit & $5909,8 \mathrm{ab}$ & 77,8 & $6008.5 \mathrm{a}$ & 79.0 \\
\hline Yıl ortalama & 5704,1 öd & & 5633.8 & \\
\hline LSD çeșit & 339,08 & & 347,36 & \\
F değeri çeşit & 10,58 & & 19,3 & \\
P değeri çeşit & 0,0003 & & 0,0001 & \\
VK (\%) & 6,38 & 7,47 & \\
\hline AyK
\end{tabular}

Aynı sütunda benzer harfler ile gösterilen ortalamalar arasında istatistiksel olarak fark yoktur. öd: Önemli değil

Şeker mısır çeşitlerinin pazarlanabilir koçan sayısı ve incelenen koçan özellikleri (koçan boyu, koçan çapı, koçanda tane sayısı, tek koçan ağırlığı ve pazarlanabilir koçan sayısı) arasındaki farklar istatistiksel olarak önemli olmuş, en düşük ve en yüksek değerler çeşitlere ve yıllara göre değişmiştir (Tablo 3, 4). Araştırmada 2019 ve 2020 yıllarında; koçan boyu 18,2-21,6 cm ve $17,1-24,1 \mathrm{~cm}$, koçan çapı $37,6-51,0 \mathrm{~mm}$ ve 46,0-52,1 $\mathrm{mm}$, koçanda tane sayısı 502,3-703,3 adet/koçan ve 544,0-780,6 adet/koçan, tek koçan ağırığı 275,6-304,0 $\mathrm{g}$ ve $188,1-316,9 \mathrm{~g}$ ve pazarlanabilir koçan sayısı $5553,4-6131,7$ adet/da ve 5423,0-6215,3 adet/da arasında değişmiştir (Tablo 3, 4). Çeşitlerin koçan özellikleri arasındaki farklılıkların pazarlanabilir koçan sayısına yansıdığı söylenebilir. En yüksek pazarlanabilir koçan sayısına sahip olan "Mirza" ve "Merit" çeşitlerinin koçan özelliklerinin de yüksek olduğu belirlenmiştir. Çeşitler arasında her iki yılda da en düşük koçan boyu, koçan çapı, koçanda tane sayısı ve tek koçan ağırlığı "Batem tatlı" çeşidinde, pazarlanabilir koçan sayısı ise birinci yıl "Bond" ve ikinci yıl "Khan" çeşitlerinde belirlenmiştir. Şeker mısırı taneleri hasat mevsimi dışında konserve şeklinde tüketildiği gibi, özellikle yaz döneminde (hasat zamanı) yaygın olarak koçanı tüketilmektedir. Bu nedenle pazarlanmasında etkili olan en önemli iki koçan özelliği boyu ve çapıdır. Amerikan (US) tüketici standartları sınıflandırmasına (US Fancy, US No. 1 ve US No. 2) göre, parselden elde edilen elde edilen taze koçanların $\% 70$ ile 79'u pazarlanabilir koçan sınıfına girmiştir (Tablo 4). Mısır alttürleri arasında kardeşlenme özelliği olan tek cins şeker mısırdır, bu nedenle kardeşlerden ve aynı bitkide çıkan ikinci koçanlar pazarlanabilir koçan sınıfı dışında kalmıştır. Çalışmamızın sonuçları ile karşılaştırmak amacıyla, Türkiye'nin değişik ekolojik bölgelerinde 
şeker mısırda koçan boyu, çapı, ağırlığı, koçanda tane sayısı ve pazarlanabilir koçan sayısına ilişkin yürütülen araştıranların bazıları aşağıda özet olarak sunulmuştur. Isparta koşullarında, şeker mısırın koçan boyu 19,2-20,9 $\mathrm{cm}$, koçan çapı 45,6-47,5 mm, koçandaki tane sayısı 713-720 adet, tek koçan ağırlığı 320,3-329,7 g ve pazarlanabilir koçan sayısı 1658-1873 adet/da (Kara ve Akman, 2002), Tokat koşullarında, koçan boyu 19,6-20,8 cm, tek koçan ağırlığı 181,0-260,5 g ve pazarlanabilir koçan sayısı 4830,0-6373,0 adet/da (Sakin ve Azapoğlu, 2017), Burdur koşullarında, koçan boyu 17,5- 22,0 mm, çapı 43,6-50,3 mm, koçanda tane sayısı 515,6-750,4 adet/koçan, ağırlığı 201,1-315,4 g ve taze koçan sayısı 10384,5-10732,0 adet/da (Yıldırkan ve Kara, 2020) ve Konya koşullarında, koçan boyu 19,5-20,8 cm, koçan çapı 48,1-51,5 mm, koçanda tane sayısı 593,0-758,0 adet/koçan ve pazarlanabilir koçan verimi 1096,31523,3 kg/da (Eser ve Soylu, 2020) arasında değiştiğini bildirmişlerdir. Şeker mısırda koçan özellikleri ve pazarlanabilir koçan sayısının yetiştirme koşullarına, çeşitlere, kardeşlenme özelliklerine, bakım işlemlerine ve koçan bağlama sayısı gibi özeliklere bağlı olarak önemli ölçüde değiştiği bildirilmiştir (Özata ve ark., 2016; Atar ve Kara, 2017; Stansluos ve ark., 2020).

\section{SONUÇ}

Burdur ekolojik koşullarında, incelenen şeker mısır çeşitlerinin koçan özellikleri ve pazarlanabilir koçan sayıları çeşitlere ve yıllara göre değişmiştir. Burdur koşullarında 83. günde "Vega ve Batem tatlı" çeşitlerinde taze koçan hasadı yapılmıştır. "Mirza, Vega, Bond ve Merit" çeşitleri yüksek koçan özelliklerine sahip olurken, şeker mısırda nihai hedef olan pazarlanabilir koçan sayısı bakımından "Vega, Mirza ve Merit" çeşitleri en yüksek değerlere sahip olmuşlardır.

Sonuç olarak; bir sebze gibi tüketilen şeker mısırın hasadının geniş bir zaman periyoduna yayılması ve pazarlamasında yüksek albeni oluşturan koçan boyu ve çapı gibi özellikler dikkate alınmalıdır. Burdur ve benzeri ekolojik koşullarda erken hasat için "Vega ve Batem tatlı, yüksek koçan değerleri için "Mirza" ve geç hasat için "Merit" çeşitleri önerilmektedir.

\section{KAYNAKLAR}

Anonim (2020). Bitkisel Üretim İstatistikleri. Türkiye İstatistik Kurumu. https://biruni.tuik.gov.tr/medas/?kn=92\&locale=tr (Erişim Tarihi: 27.10.2020)

Atar, B., Kara, B. (2017). Farklı derinliklerde çizilere ekimin şeker mısırın taze koçan verimi ve bazı koçan özelliklerine etkisi. DERIM, 34(2): 182-185.
Ağaçkesen M.N., Ökten, A. (2020). Farklı zamanlarda yapilan hasadin merit tatli misir çeşidinde (Zea mays L. saccharata Sturt) taze koçan verimi ve bazi verim unsurlarina etkisi. Kahramanmaraş Sütçü Imam Üniversities, Tarım ve Doğa Dergisi, 23(1): 69-76.

Eser, C., Soylu, S. (2020). Orta Anadolu koşullarında şeker mısır çeşitlerinin taze koçan verimi ile bazı agronomik özelliklerinin belirlenmesi. Bahri Dağdaş Bitkisel Araştırma Dergisi, 9(2): 147-157.

Kara, B., Akman, Z. (2002). Şeker mısırında (Zea mays saccharata Sturt.) koltuk ve uç alma ile yaprak sıyırmanın verim ve koçan özelliklerine etkisi. Akdeniz Üniversitesi Ziraat Fakültesi Dergisi, 15(2): 9-18.

Kara, B. (2011). Fresh ear yield and growing degree-days of sweet corn in different sowing dates in southwestern Anatolia region. Turkish Journal of Field Crops, 16(2):166-171.

Kara, B., Uygur, V. (2020). Organic or conventional agriculture? A Study on yield and nutritional status of sweet corn. Maydica, 65:1-7.

Köycü, C., Yanıkoğlu, S. (1987). Samsun ekolojik şartlarında mısır (Zea mays L.) çeşit ve ekim zamanı üzerinde bir araştırma, Türkiye'de Mısır Üretiminin Geliştirilmesi, Problemler ve Çözüm Yolları Sempozyumu, 23-26 Mart 1987, 287302, Ankara

Lizaso, J.I., Boote, K.J., Cherr, C.M., Scholberg, J.M.S., Casanova, J.J., Judge, J., Jones, J.W. Hoogenboom, G. (2007). Developing a sweet corn simulation model to predict fresh market yield and quality of ears. Journal American Society. Horti Science, 132(3):415-422.

Özata, E., Geçit, H.H., Ünver İkincikarakaya, S. (2016). Orta Karadeniz ekolojik koşullarında şeker mısırda (Zea mays saccharata Sturt.) değişik ekim sıklıkları ve azot dozlarının verim öğelerine etkisi. Tarla Bitkileri Merkez Araştırma Enstitüsü Dergisi, 25 (Özel sayı-1): 74-80.

Sakin, M.A., Azapoğlu, Ö. (2017). Tokat-Kazova koşullarında şeker mısırın (Zea mays saccharata Sturt.) taze koçan ve tane verimi ile bazı verim ve kalite özelliklerine azot ve fosforun etkileri. Gaziosmanpaşa Üniversitesi Ziraat Fakültesi Dergisi, 34(3): 46-55.

Sönmez, K., Alan, Ö., Kinaci, E., Kinacl, G., Kutlu, İ., Başçiftçi, Z.B., Evrenosoğlu, Y. (2013). Bazı şeker misiri çeşitlerinin (Zea mays saccharata Sturt) bitki, koçan ve verim özellikleri. Süleyman Demirel Üniversitesi Ziraat Fakültesi Dergisi 8(1):28-40.

Stansluos, A.A.L., Öztürk, A., Kodaz, S. (2020). Agronomic performance of different sweet corn varieties in the highest plain of Turkey: Quality characteristics. Atatürk Üniversitesi Ziraat Fakültesi Dergisi, 51(3): 249-257.

Szymanek,, M., Dobrzañski, B., Niedziólka I., Rybczyñski, R. (2006). Sweet corn harvest and technology, physical properties and quality. Bohdan Dobrzański Institute of Agrophysics of Polish Academy of Sciences, Lublin 2006, $1^{\text {st }}$ Edition - ISBN 83-89969-55-6.

Yıldırkan, Ü., Kara, B. (2020). Burdur ikinci ürün koşullarında bazı şeker mısır (Zea mays L. var. saccharata) çeşitlerinin taze koçan özellikleri. Türk Bilim ve Mühendislik Dergisi, 2(1): 30-33. 